\title{
ENTRE ACCIOLYS E CABRAIS: HERANÇA E REPRODUÇÃO DO CAPITAL POLÍTICO FAMILIAR NA ARATANHA CEARENSE
}

\begin{abstract}
Alan Philipe Moreira Silveira ${ }^{1}$
Resumo: O presente artigo tem por finalidade analisar a estruturação e reprodução do poder político-familiar dos Cabrais-Acciolys numa perspectiva de longa duração, no âmbito da política institucional dos municípios de Pacatuba e Guaiúba-Ceará, região denominada Aratanha Cearense. Para tanto, foi empreendida uma pesquisa documental, possibilitada pelo acesso a notícias de jornais dos séculos XIX e XX, disponibilizados pela Hemeroteca Digital Brasileira da Biblioteca Nacional, analisados juntos a elaboração das genealogias que envolvem cinco gerações das supracitadas famílias, o que proporcionou apontar as suas relações de parentesco e continuidade nos quadros político-administrativos locais. Além disso, realizou-se uma pesquisa bibliográfica para discutir o conceito de capital político-familiar (MONTEIRO, 2016) a partir do exemplo da família CabralAccioly.
\end{abstract}

Palavras-chave: História Política. Família. Poder local.

\section{BETWEEN ACCIOLYS AND CABRAIS: INHERITANCE AND REPRODUCTION OF THE FAMILY POLITICAL CAPITAL IN ARATANHA CEARENSE}

\begin{abstract}
The purpose of this article is to analyze the structuring and reproduction of Cabrais-Acciolys politicalfamily power in a long-term perspective within the institutional politics of the Pacatuba and Guaiúba cities, a region called Aratanha Cearense. In order to do so, a documentary research was carried out, made possible by the access to news stories of the 19th and 20th centuries, made available by the National Digital Library of the National Library, analyzed together the elaboration of genealogies involving five generations of the families above, which their relations of kinship and continuity in the local political-administrative frameworks. In addition, a bibliographical research was conducted to discuss the concept of family-political capital (MONTEIRO, 2016) based on the example of the Cabral-Accioly family.
\end{abstract}

Keywords: Political History. Family. Local power.

\section{Introdução}

O Ceará, estado do Nordeste brasileiro, é território onde as oligarquias de base familiar constituíram e perpetuaram domínios políticos históricos, com destaque para o "acciolysmo", que na figura de Antônio Pinto Nogueira Accioly (1840-1921) exerceu, de 1896 a 1912, um extenso, nepótico e violento controle da política (LEMENHE, 1995; FARIAS, 2015). No entanto, a relação entre família e política não se encontra unicamente

\footnotetext{
${ }^{1}$ Bacharel Interdisciplinar em Ciências Humanas e graduando em Licenciatura em História pela Universidade da Integração Internacional da Lusofonia Afro-Brasileira (UNILAB). E-mail: alanphilipe90@ @mail.com
} 
situada em um passado de predominância coronelística. Como questão contemporânea, o imbricamento entre família e política suscita apontar a estruturação, reprodução e permanência dos Cabrais-Acciolys na administração e política institucional local desde fins do século XIX entre Pacatuba e Guaiúba, numa região conhecida como Aratanha.

A Pacatuba e a Guaiúba da primeira metade do século XIX não passavam de simples povoados, a primeira se sobressaindo ao tornar-se, em 1848, sede de distrito da Vila de Maranguape, ambas constituídas por sítios, terras que em sua maioria pertenciam aos Costa e Silva, mais especificamente aos irmãos José Antônio da Costa e Silva (1805-1867) e Domingos da Costa e Silva (1804-1862), herdeiros do Sargento-mor Albano da Costa dos Anjos (1768-1822) e pioneiros no cultivo do café nessa região. Um relativo crescimento do povoado da Pacatuba permite a sua elevação a categoria de Vila pela Lei Provincial $n^{\circ} 1284$ de 8 de outubro de 1869, um mês depois a resolução $n^{\circ} 1305$ de 5 novembro cria a freguesia, elevando como matriz a capela de Nossa Senhora da Conceição. A inauguração da freguesia ocorre a 6 de fevereiro de 1870, com a posse do vigário Pe. Bernardino de Oliveira Memória (1832-1899).

O município de Guaiúba possui 32 anos de emancipação política, completados no 17 de março 2019. No entanto, a permanência de determinadas famílias em posições de domínios políticos acha-se fincada na história desse território, estendendo-se por mais de um século antes do tão almejado desmembramento de Pacatuba. Nessa cidade, a família Cabral-Accioly venceu cinco das oito eleições municipais, além de influenciar diretamente na vitória de um não membro da família. As ruas, rodovias, escolas e demais logradouros públicos encontramse circunscritos por nomes hoje pouco recorrentes na lembrança dos habitantes da jovem cidade, mas que se acham agregados aos sobrenomes Cabral-Accioly, indicando ali que há muito se localizam como famílias de prestígio, como elite política municipal, que têm reproduzido posições e cargos na Aratanha Cearense que percorrem desde as últimas décadas do Império (1822-1889) — período da instalação da Câmara da Pacatuba, em 26 de abril de 1873 — passando pela República Velha (1889-1930), chegando ao Regime Militar (19641985) e permanecendo na Redemocratização ao reafirmarem seu domínio político na Guaiúba, ao vencerem a primeira eleição após a emancipação desse município em 17 de março de 1987.

Desta feita, ao apontarmos a interação de tais famílias com o poder local, evidenciamos a estruturação histórica do seu capital político-familiar, imprescindível no 
acesso aos espaços de disputas pelo prestígio, quando atua materializando o elemento simbólico quase infalível na garantia do sucesso eleitoral: o sobrenome/nome familiar. Como num ritual de transmissão, o neófito das famílias políticas, aquele detentor da "distinção", é conduzido a ocupar um lugar na estrutura do poder antes ocupado por seus parentes, conservando e prolongando sua tradição familiar de domínio (MONTEIRO, 2016a).

\section{Os Accioly em Guaiúba}

O primeiro dos Acciolys a chegar em Guaiúba, André Accioly de Vasconcellos, Andrezinho, como o chamavam por ter recebido o nome do avô paterno, o sargento paraibano André Accioli de Vasconcellos, nasceu no Riacho do Sangue, hoje Jaguaretama-Ceará, a 23 de setembro de 1822, filho de Manoel da Silva Pereira e de Antônia Maria de Jesus. Casandose na capela de Nossa Senhora da Penha da Vila de Maranguape a 10 de outubro de 1841 com Mathilde Joaquina de Castro Silva (? +1889), viúva de Antonio Gomes do Valle.

Andrezinho teria chegado a Guaiúba por volta de 1854 já com alguns filhos crescidos, quando logo se torna encarregado da produção de café de um dos sítios do Comendador Antonio Cabral de Mello (1807-1886), este, ao terminar a colheita de um ano teria lhe doado o equivalente a toda uma safra, o que permitiu ao Andrezinho adquirir uma boa propriedade, bem localizada, em um ponto do povoado chamado de "Côrte". No exercício de funções públicas Andrezinho se destacou como figura de grande prestígio na povoação da Guaiúba.

Dois dos oito filhos de Andrezinho adentraram na vida política, Rogério Accioly de Vasconcellos (1856? - 1934), com muita brevidade, foi eleito entre os Conservadores para o cargo de Juiz de Paz da Pacatuba em julho de 1882. Porém, sem extensa participação, possivelmente pelo fato de ter-se transferido, primeiramente para a Vila do Acarape, no Maciço de Baturité, onde foi comerciante, e em seguida para Fortaleza, onde trabalhou como Contínuo na Secretaria do Liceu do Ceará. O outro, Antônio Accioly de Vasconcellos, com maior ênfase, inicia a vida pública por volta de 1877 como membro da comissão de socorros da seca no distrito da Guaiúba, ao lado de José Correia de Mello, seu compadre, que acabara de encerrar seu mandato na câmara da Pacatuba. ${ }^{2}$ Em 22 de dezembro de 1880, anuncia no jornal "O Cearense" que de sociedade com os irmãos Rogério e José Accioly abriram a firma

\footnotetext{
${ }^{2}$ Mercantil. 4 de novembro de 1877.
} 
“Accioly \& Irmãos”, com funcionamento no povoado da Guaiúba e na cidade de Baturité, destinada ao comércio de gêneros nacionais e estrangeiros.

Ainda em 1889 é nomeado subdelegado do distrito da Guayuba. No ano seguinte, em conformidade com o Decreto n. ${ }^{\circ} 639$ de 12 de agosto, expedido pelo governo provisório do estado do Ceará, é designado presidente da comissão pela qual se encarrega de executar, inspecionar e dirigir os trabalhos de recenseamento do referido distrito. ${ }^{3}$ Após a instauração da República no Brasil, se inicia na maioria das províncias uma sucessiva criação de clubes republicanos: o da Pacatuba tem sua organização em dezembro de 1889, onde logo Antônio Accioly passa a figurar. No entanto, em 26 de abril de 1904 os membros desse grupo se dividirão para formar o Partido Revisionista, para onde migra Antônio Accioly e os demais que de imediato se colocam como oposição ao governo de Nogueira Accioly, e consecutivamente aos seus aliados na câmara da Pacatuba.

O que os Revisionistas da Pacatuba alegavam era que, ainda em 1894, a Câmara nada devia, possuía crédito, prédio mobiliado, para em tão curto tempo instalar-se o caos administrativo. ${ }^{4}$ Tais críticas seguiam diretamente para a figura do Intendente municipal Coronel João Carlos da Costa Pinheiro, ferrenho aliado de Nogueira Accioly, que mesmo a oposição revisionista não pôde suplantar, permanecendo na intendência pelo mesmo período de tempo que Nogueira Accioly permanece no governo do estado (1896-1912), ainda mais, elegendo-se deputado estadual para três legislaturas (1901-1912).

Na eleição de 1904 para a câmara da Pacatuba, saem derrotados os Revisionistas, sem elegerem um só vereador, fato que atribuem as fraudes organizadas pelo Intendente João Carlos. Tais acusações iam desde o sumiço da urna do distrito da Guaiúba, território de Antônio Accioly — onde a oposição contou com maior votação - , ao desaparecimento dos nomes nas listas eleitorais. ${ }^{5}$

Com a deposição de Nogueira Accioly em 24 de janeiro de 1912, e o consecutivo afastamento do Coronel João Carlos, assume Antônio Accioly de Vasconcellos o cargo de intendente municipal a 26 de janeiro. O que não se imaginava era que ainda em novembro daquele conturbado ano, Antônio Accioly, na idade de 65 anos, iria falecer. Antônio Accioly de Vasconcellos era viúvo de Maria Facundo de Vasconcellos, filha do segundo casamento do abastado fazendeiro, ex-juiz de paz e ex-vereador João Facundo de Menezes (+1885) com

\footnotetext{
${ }^{3}$ Libertador. 9 de outubro de 1890.

${ }^{4}$ Ao Eleitorado da Pacatuba. Jornal do Ceará. 27 de abril de 1904.

${ }^{5}$ O Governo roubado. Jornal do Ceará. 9 de maio de 1904.
} 
Maria Francisca dos Santos. Com a família Facundo de Menezes, os Acciolys contraem não só o casamento de Antônio, mas também o de Liberalina, outra filha do velho Andrezinho, que se casa a 8 de fevereiro de 1873 com o Tenente-cirurgião Alferes João Facundo de Menezes Filho.

A vaga deixada na intendência pela morte de Antônio Accioly no primeiro ano de exercício do cargo, logo será preenchida. Para ocupá-la, é nomeado o jovem agricultor e comerciante Esaú Accioly de Vasconcellos (1889-1975), filho de Antônio. Esaú permanecerá como intendente da Pacatuba até março de 1914, mês em que o presidente do estado Marcos Franco Rabello, o qual os Acciolys da Guaiúba apoiavam desde aproximadamente 1911, seria deposto pela "Sedição de Juazeiro"6 . Após esse período, Esaú transfere-se para Fortaleza onde irá cursar a Escola de Agronomia, na qual após formado exercerá os cargos de secretário e professor.

Em 23 de março de 1926 casa-se com Hilda de Castro Fradique (1900-1989), filha do rico negociante português Cel. Manoel Fernandes Fradique (1857-1933). Esaú ingressou no Ministério da Agricultura em 1936 pela Diretoria do Ensino Agrícola, daí é destacado para administrar o Horto Florestal de Ubajara na Serra da Ibiapaba e em Guaiúba dirige o Campo Experimental de Sementes em propriedade de 300 hectares, doação sua à União, destinada ao Fomento Agrícola. Logo depois do período que Esaú ocupou a intendência da Pacatuba, dá-se um grande intervalo na presença dos Acciolys na política local, apenas com a aparecimento de um deles, o Major Lindolpho Accioly Pinheiro, primo de Esaú, exercendo um mandato na câmara municipal entre os anos 1920 e 1924. O Major Lindolpho foi também rico comerciante, tinha forte papel a frente da comunidade guaiubense em relação a administração do aspecto religioso, coordenando as festas da igreja. Casado e sem filhos, deixa viúva a senhora Maria Amélia de Araújo.

Essa ausência dos Acciolys em cargos públicos entre Pacatuba e Guaiúba será rompida quando Antônio Fradique Accioly (1927-2017), filho de Esaú Accioly com Hilda Fradique, formado em Ciências Sociais e Jurídicas pela Universidade Federal do Ceará (UFC) em 1950, ingressará no Ministério Público em 1952, assumindo o cargo de Promotor de Justiça da Comarca de Pacatuba.

\footnotetext{
${ }^{6}$ A revolta ou Sedição de Juazeiro foi um confronto ocorrido entre dezembro de 1913 e março de 1914 em Juazeiro do Norte-Ceará, envolvendo as oligarquias cearenses — especialmente as sertanejas - e o governo federal, tendo em vista a derrubada do governador Franco Rabelo e o fim da interferência do poder central na política estadual.
} 


\section{Acciolys e Cabrais: parentesco e política}

Em maio de 1956 Antônio Fradique Accioly contrai matrimônio com a conterrânea Elzenir Cabral Torres (1937). Filha do segundo casamento de Raimundo Bandeira Torres (1907-1986) com Adelina de Araújo Cabral (1916-1965), descende, por linha materna, de duas das mais importantes proprietárias rurais de Guaiúba, que assim como os Acciolys, apresentam extensa ocupação de cargos públicos e eletivos que remontam ao período imperial. Seu pai, advindo de uma família de comerciantes fixados nos distritos de Água Verde e Guaiúba, também foi vereador da Pacatuba dos anos 1947 a 1958, ocupando a chefia do partido da União Democrática Nacional (UDN) por longo período.

Já a mãe de Elzenir, Adelina de Araújo Cabral, era filha de Manuel Hermínio Cabral "Filho" (1886-1929), comerciante e vereador da Pacatuba no período de 1924 a 1928, casado com Maria Augusta de Araújo (1890 -?). Em concordância com Rêgo (2008), observamos que o funcionamento do casamento exógamo imprimiu sobre as famílias Araújo-Cabral e CabralAccioly significativo aumento e reforço do prestígio político, para além das alianças de significado econômico, foi a acumulação e transmissão da herança política o principal capital desenvolvido por essas famílias.

Além do casamento de Maria Augusta de Araújo com Manuel Hermínio Cabral "Filho", casaram-se o coronel João Augusto de Araújo (1884-1957), irmão de Maria Augusta, com Maria do Carmo Cabral (1887-1958), irmã de Manuel Hermínio "Filho”. O coronel João Augusto, assim como os anteriores, figurava entre os abastados comerciantes da Guaiúba, chegando a estender seu comercio para a capital cearense. João Augusto foi prefeito da Pacatuba em duas legislaturas, a primeira de 1922 a 1924 e a última entre 1929 e 1932, quando foi eleito secretamente pela câmara em novembro de 1928 (LOUREIRO, 2006).

Retomando a ascendência de Elzenir e a atuação dos Cabrais na Aratanha Cearense, encontraremos seu bisavô materno, Manoel Hermínio Cabral "Pai" (? - 1892) entre os suplentes de juiz de paz eleitos para o quadriênio 1876 - 1880. Hermínio Cabral "Pai" também esteve entre os camaristas da terceira bancada da Câmara da Vila de Pacatuba (18811883), no ano seguinte ocupou o cargo de $2^{\circ}$ suplente de juiz substituto, do qual é exonerado em $1885 .^{7}$

\footnotetext{
${ }^{7}$ Cearense. 14 de fevereiro de 1885 .
} 
Revista NEP - Núcleo de Estudos Paranaenses, Curitiba, v. 5, n. 2, dez. 2019

Em 30 de julho de 1889 foi designado pelo governo provincial para a função de Comissário Geral dos Socorros Públicos do termo da Pacatuba, serviços em consequência de mais uma seca naqueles anos. Nessa função, Manoel Hermínio protagonizou inúmeras polêmicas, desde acusações de desmandos e desvios dos mantimentos dos socorros a desavenças que travou com ex-aliados e familiares, algumas delas estampadas nas páginas do jornal conservador Pedro II. À frente da Comissão de Socorros, foi acusado de transportar publicamente para sua residência, em burros seus, os tijolos feitos as custas dos socorros e fraudar a pesagem da carne, advinda do abate do seu próprio rebanho, que se destinava a distribuição entre os famintos, sem sofrer a mínima advertência por parte dos fiscais. ${ }^{8}$ Referido como "gênio perigoso", "incorrigível", tratava com uso da força os que lhe contrariavam, invadindo, açoitando e mandando prender os desvalidos com a influência que exercia sobre o juiz municipal, Dr. Abel Garcia. ${ }^{9}$ Em janeiro de 1890, após ser nomeado para o conselho de intendência municipal ${ }^{10}$, recusa alegando grandes ocupações. Foi Tenentecoronel da Guarda Nacional, nomeado em fevereiro de 1891, no entanto o jornal "A República" de 28 de abril de 1892 notifica a perca do posto por não solicitação da patente, possivelmente não efetuada por consequência de seu falecimento.

Hermínio Cabral "Pai" era filho do Comendador Antônio Cabral de Mello (18071886) e da sua esposa Henriqueta Hermina Cabral (? - 1896). O Comendador Cabral de Mello era português, da Ilha de São Miguel nos Açores, de onde chegara na Aratanha ainda jovem. Sendo grande proprietário de mão de obra escravizada, construiu significativa fortuna no ramo agrícola, estabelecendo ampla descendência.

Entre os demais filhos do Comendador Cabral, ganhou destaque na sociedade cearense Raymunda Cabral Theóphilo (? - 1928), casada com o farmacêutico e escritor Rodolfo Marcos Theóphilo (1863-1932). Raymunda foi umas das principais mulheres envolvidas na causa da Abolição no Ceará, representando a vila da Pacatuba na sessão solene de "libertação total da província" em março de 1884. ${ }^{11}$ Ficou conhecida como a "mãe dos pobres". Outra filha, Maria do Carmo Cabral e Silva (1856-1942), casou-se com o poeta, folclorista e escritor Juvenal Galeno da Costa e Silva (1836-1931), filho do "Barão do Café" da Aratanha. Juvenal foi subdelegado de polícia da Pacatuba, deputado provincial no biênio 1858-1859, e como

\footnotetext{
8 Pedro II. 14 de novembro de 1889.

9 Ibidem. 27 de outubro de 1889.

${ }^{10}$ Libertador. 16 de janeiro de 1890.

${ }^{11}$ Ibidem. 14 de março de 1884.
} 
membro do conselho diretor da Instrução Pública, exerceu a função de inspetor literário da comarca da capital. ${ }^{12}$ Era vereador da Pacatuba quando transferiu sua residência para Fortaleza em 1888, deixando uma vaga na câmara. Por fim, o Dr. José Welligton Cabral de Mello (1856 - 1926), médico, formado em 18 dezembro de 1883 pela Faculdade de Medicina do Rio de Janeiro. Foi lotado na Inspetoria de Higiene do Ceará, para a qual foi nomeado em janeiro de 1890 delegado de higiene pública da Pacatuba ${ }^{13}$, sendo naquele período o único médico da cidade. Foi vereador no biênio 1891-1892, e era ele o irmão o qual Hermínio Cabral "Pai" nutria as maiores desavenças, expostas no jornal Pedro II como de motivação familiar, visto o Dr. José Cabral ser preferivelmente o procurador do moribundo pai, o rico Comendador Cabral de Mello. ${ }^{14}$

Toda a extensa ascendência política de Elzenir Cabral Torres dará completude ao capital político dos Acciolys, sendo mais uma vez o casamento o fator conciliante na manutenção da estrutura de poder dessas famílias. Observamos tal alinhamento quando nas eleições de outubro de 1962 Antônio Fradique Accioly foi eleito vereador com a maior votação. Ocupando o espaço do sogro na UDN, o promotor da Pacatuba retoma a presença política dos Acciolys na Aratanha Cearense, agora potencializado por sua união com uma Cabral.

Nas eleições de 1966, Antônio Fradique Accioly salta de vereador para prefeito eleito em chapa única do ARENA. Não se reelege nas duas eleições seguintes, mas torna-se viceprefeito na composição com Isaac Newton Campos pelo PDS em 1982, num mandato que duraria seis anos. É exatamente nesse período que a Guaiúba será desmembrada do município de Pacatuba pela lei estadual $\mathrm{n}^{\circ} 11.301$ de 1987, ficando com uma população de aproximadamente 17 mil habitantes na época. Sua primeira eleição transcorre em 15 de novembro de 1988, onde sai vitorioso o recém-formado em direito, Antônio Carlos Torres Fradique Accioly.

Na data da eleição, Antônio Carlos contava apenas 23 anos de idade, sendo o mais jovem prefeito eleito entre os 25 municípios cearenses emancipados em 1987, dispondo nesse pleito da ajuda e influência do pai, o ex-vereador, ex-prefeito e então vice-prefeito da Pacatuba, Antônio Fradique Accioly. Antonio Carlos seria prefeito por mais dois mandatos, de 2000 a 2008 e elegeria o primo Marcelo de Castro Fradique Accioly seu sucessor.

\footnotetext{
${ }^{12}$ A Constituição. 1872.

${ }^{13}$ Libertador. 18 de janeiro de 1890.

${ }^{14}$ Pedro II. 27 de outubro de 1889.
} 
Mais uma vez, a eleição municipal de outubro de 2016 elevou um Accioly a prefeitura de Guaiúba, Marcelo Fradique Accioly retorna ao posto após uma episódica derrota da família na disputa eleitoral do ano de 2012, o que suscita um rompimento nas relações políticofamiliares com o primo. No entanto, Marcelo é o quinto membro da parentela dos Acciolys a ocupar a vaga do executivo entre os municípios da Pacatuba e Guaiúba, dando continuidade a uma atividade hereditária e supostamente naturalizada pela ocupação do mesmo cargo na política.

José Marciano Monteiro (2016b) chama atenção para o processo de hereditariedade na política, apontando para a formação de uma certa "nobreza", aquela que dispõe do poder e do patrimônio político acumulado pelo grupo familiar ao longo dos tempos, legitimado e transmitido para filhos, netos, bisnetos e sobrinhos como herança resultante do controle e dominação das instâncias representativas. É recorrente que se encontre as famílias tradicionais como produtoras das narrativas a respeito da sua existência, elaboradas em discursos que as colocam em sintonia com a construção material e simbólica do território em que estão localizadas. Nesse sentido, Araújo (2016) concebe a cidade como produção textual, como relato direcionado ao interesse das elites, acrescentando que "[...] a representação de uma cidade - a sua 'imagem ideal', o seu 'passado idílico' e as suas tradições — é uma arma inventada e alimentada por suas elites tradicionais e é usada para justificar poderes e privilégios destes grupos sobre o restante da sociedade a sua volta" (ARAÚJO, 2016, p. 48).

Compreendidas como pertencentes ao território desde longínquas gerações, as famílias tradicionais localizam-se a partir de um espaço privilegiado no discurso que as produziu e reproduz, sempre sustentando-as simbolicamente na sua relação com o imaginário da cidade, o que as confere o ideal de primeiros habitantes, de benfeitoras, construtoras, chegando a legitimá-las como donas do lugar.

Para Adilson Filho (2002, p. 20), essa posição de poder “[...] produz discursos e imagens sobre a cidade que se concretizam na própria identidade dos seus habitantes. Muito embora nem sempre sejam homogêneos, eles aventam a possibilidade de constituição de um imaginário mais ou menos coerente em torno da cidade".

Com o discurso da tradicionalidade, as famílias do poder fazem encarnar sua dominação através de discursos que estereotipam e demarcam lugares. Úteis a manutenção do poder político das famílias tradicionais, os dominados coabitam com a prática e os mecanismos de produção da diferenciação, assumem para si e naturalizam o seu lugar passivo 
no imaginário da cidade. Adilson Filho (2002) ainda acrescenta que tal naturalização circunscreve a cidade e seus habitantes tão arraigadamente que embora idealizem mudanças, não conseguem, por estarem determinados por um passado arcaico, embarreirados pelo que é comumente familiar e subjetivamente intransponível.

Monteiro (2013) também pontua que, a incorporação desses valores como legítimos por aqueles desprovidos de capitais, ou seja, os dominados dentro da estrutura social, acabam por reproduzir a concepção do dominante como se ela não pudesse ser alterada, compreendendo-a como única realidade possível e verdadeira. Esse ponto de vista atua reafirmando posições sociais históricas e desiguais no âmbito da cidade, legitimando aqueles oriundos de famílias políticas tradicionais como únicos aptos para o exercício do poder, enquanto limita o restante da sociedade para o cumprimento de atividades secundarias. Nesse sentido, compreende-se a cidade como socialmente produzida, elaborada diante da narrativa que a define sob múltiplos estereótipos, encoberta por traz do imaginário compartilhado e assumido por todos, porém, evidenciada como constructo resultante do interesse dos dominantes. Como sustentáculo dessa construção, o imaginário que se vivencia coletivamente é continuamente reafirmado pela ação dos "intelectuais orgânicos": professores, escritores, radialistas, e principalmente os memorialistas, estes, detentores e disseminadores da história e memória local sob tutela das famílias tradicionais (ARAÚJO, 2016).

No Brasil, a família e o poder sempre estiveram relacionados em grande sintonia e organizados em torno do Estado, ditando toda ordem dos interesses públicos a semelhança dos privados. André Heráclio do Rêgo (2008) assinala que, possivelmente no Brasil a família tenha atingido o mais alto grau de interação com o poder político, observada a sua relação com a administração da ordem econômica e social. Essa interrelação das famílias com as instituições pela ocupação das funções da administração pública é recorrente do início da formação do país, onde a conquista da terra e o exercício da ordem e mando sobre ela partia de um grande núcleo familiar organizado em torno do poder absolutista do pater-familias. Continuando as composições familiares na política e nas instituições mesmo ultrapassado o período da República Velha (1889-1930), em que se acentua as oligarquias e é também chamado de "República dos Coronéis", Vilaça e Albuquerque (2006) vão entender as práticas semelhantes daquele sistema como uma "revivescência do coronelismo".

No entanto, Monteiro (2016a) compreende que o poder advindo das relações e conexões familiares tem garantido a sobrevivência das famílias políticas em volta do Estado e 
das suas instituições desde a colônia, retroalimentando o poder econômico e simbólico que determina a posição social superiormente localizada de grupos que formam verdadeiras linhagens na política. A longa trajetória das famílias políticas em sua contínua relação com o Estado e a ocupação de cargos, engendra capitais materiais e simbólicos que as distingue e as reforça na sua permanente atividade. O sobrenome ou nome familiar é a ferramenta caracterizadora desse patrimônio simbólico que se conecta ao indivíduo pertencente à família política, legitimando a sua participação e potencializando seu sucesso em disputas eleitorais. Dessa forma, o capital político-familiar tende a direcionar sempre a um lugar em evidência, tanto no campo das disputas eleitorais quanto na ocupação de cargos administrativos, determinados sujeitos saídos dos arranjos e rearranjos familiares propiciados pela configuração de forças desses capitais, ao cabo que "muda-se o nome, permanece o sobrenome. Muda-se o agente, permanece a família. É a mudança na permanência” (Idem, 2016a, p. 50). Essa "mudança na permanência" mantêm o recrutamento de jovens políticos carregando em seus slogans a estratégia discursiva do "novo", da própria ideia de mudança e de renovação. Toda vez que o domínio dos predecessores cessa ou entra em decadência, o capital político-familiar reveste novos corpos, novas roupagens e outros agentes que herdarão a profundidade histórica da família em sua relação com poder, num movimento sutil que imporá sujeitos modernos, mas constituídos pela tradição.

Monteiro (2016a) operacionaliza o conceito de capital político-familiar pela análise das conexões envolventes dos capitais social e econômico das estruturas familiares, mensurando sua constituição e presença numa perspectiva de longa permanência, explicitadas mediante as relações de parentesco na política, mídia, judiciário e economia. Somadas à intersecção entre família e política, Monteiro e Ferreira (2017) acrescentam o estudo das dimensões da hereditariedade como questão explícita a lógica de reprodução dos grupos familiares de elite, fundamental para que pensemos em nossa pesquisa o modo de "transmissão linear" que estruturou/estrutura o poder político dos Cabrais-Acciolys entre Pacatuba e Guaiúba, evidenciado na ocupação do executivo municipal pelo bisavô, avô, pai e neto, num espaço temporal centenário entre os dois municípios.

\section{Considerações finais}


Como lugar de inscrição material e simbólico, buscamos compreender a cidade como supõe Araújo (2016), ou seja, como idealização e narrativa de um passado redivivo, elaborado e relacionado com a trajetória das famílias tradicionais, como espaço indissociado do esforço que as mantêm sob o status de "verdadeiras donas do lugar". Assim como a partir dessa compreensão, compactuamos com a necessidade acentuada por Adilson Filho (2002), de se questionar a identidade fixa e os estereótipos conservados pelo imaginário das cidades em torno da sua elite, que inalteradamente conserva posições estratégicas de poder que estruturam sua dominação a partir da história e memória local.

Tal domínio perpassa pela estratégia de manutenção do poder no seio familiar, ao atravessarem a história política de Pacatuba e Guaiúba, os Acciolys e Cabrais encarnam naturalizações e povoam mentalidades. A força do nome da família, símbolo do capital político-familiar, é até então a marcante característica de conservação desse grupo familiar nas relações centrais de participação e consequente continuidade nos cargos administrativos e eletivos até os dias de hoje.

\section{Referências Bibliográficas}

ADILSON FILHO, José. A Cidade Atravessada: Velhos e novos cenários na política belojardinense (1969-2000). 2002. 135 f. Dissertação (Mestrado) - Programa de Pósgraduação em História, Centro de Filosofia e Ciências Humanas, Universidade Federal de Pernambuco, Recife, 2002.

ARAÚJO, Raimundo Alves de. "Quem não tem padrinho morre pagão": um modelo para se entender o clientelismo sertanejo. In: SANTOS, Carlos Augusto dos; MELO, Francisco Dênis; ARAÚJO, Reginaldo Alves de. (Orgs.). Nas trilhas do sertão: escritos de cultura e política nos interiores do Ceará. 3. v. Sobral: Sertãocult, 2016. Cap. 3. p. 47-81.

FARIAS, Airton de. História do Ceará. 7. Ed. Fortaleza: Armazém da Cultura, 2016.

LEMENHE, Maria Auxiliadora. Família, Tradição e Poder: o caso dos coronéis. São Paulo: ANNABLUME/Edições UFC, 1995.

LOUREIRO, Paz. Pacatuba: Formação Histórica e Política Eleições 1873 - 2004. Fortaleza: Integráfica, 2006. 290 p.

MONTEIRO, José Marciano. Família, Poder Local e Dominação: um estudo sobre os processos de disputas políticas entre a(s) família(s) Ernesto-Rêgo em Queimadas/Paraíba. Campina Grande, 2009. 168p.

Famílias, Cultura Política e Dominação no Semiárido Nordestino: o caso de Queimadas-PB. Raízes, Campina Grande, v. 33, n. 1, p.149-164, 2013. 
Revista NEP - Núcleo de Estudos Paranaenses, Curitiba, v. 5, n. 2, dez. 2019

. A Política como Negócio de Família: para uma sociologia das elites e do poder político familiar. São Paulo: LiberArs, 2016a.

Parentesco e representação política: a força do capital político familiar na $54^{\mathrm{a}}$ legislatura no Congresso Nacional. Revista Nep: (Núcleo de Estudos Paranaenses), Curitiba, v. 2 , n. 2, p.561-579, maio 2016 b.

; FERREIRA, Rafael de Farias. A reprodução das famílias políticas e as dimensões da hereditariedade no estado da Paraíba. Revista Nep: (Núcleo de Estudos Paranaenses), Curitiba, v. 3, n. 3, p.195-214, ago. 2017.

RÊGO, André Heráclio. Família e Coronelismo no Brasil: uma história de poder. São Paulo: A Girafa Editora, 2008.

VILAÇA, Marcos Vinicios; ALBUQUERQUE, Roberto Cavalcanti de. Coronel, coronéis: apogeu e declínio do coronelismo no Nordeste. 5. ed. Rio de Janeiro: Bertrand Brasil, 2006. 208 p.

\section{Sites:}

APRECE. Breve Histórico da Vida de Antonio Fradique Accioly. [mensagem pessoal] Mensagem recebida por: <alanphilipe90@ gmail.com>. em: 11 ago. 2017.

LEITÃO FILHO, Sinval. Memórias de Guaiúba. Elaborada por Antônio Carlos Sales Paiva. Disponível em: <http://paroquiamissionaria.blogspot.com>. Acesso em: 10 jul. 2018.

RIBEIRO, Soriano. Antonio Carlos Torres Fradique Accioly. 2008. Disponível em: <https://sorianoribeiro.blogspot.com/2008/04/antonio-carlos-torres fradiqueaccioly.html>. Acesso em: 18 jul. 2018.

Recebido em: 19out. 2019

Aceito em: 26 nov. 2019 